Заключение. Анализируя вышеизложенное, можно сделать следующие выводы: из рассмотренных четырех схем схема расстановки на почвообрабатывающем орудии, выполненном по схеме лемешно-отвального плуга общего назначения чизельных рабочих органов, является рациональной и обеспечивает минимальное тяговое сопротивление за счет применения чизельных рабочих органов, взаимодействующих с обрабатываемым пахотным слоем по полублокированной схеме. Лемешно-отвальные плуги, комплектованные чизельными рабочими органами, обеспечивают минимальное тяговое сопротивление в сравнении с известными чизельными плугами одинаковой ширины захвата.

Плужную расстановку чизельных рабочих органов на раме почвообрабатывающего орудия нужно использовать для проектирования новых чизельных почвообрабатывающих орудий.

\section{СПИСОК ЛИТЕРАТУРЫ}

1. СТО АИСТ 104.6 - 2003. Стандарт организации. Испытания сельскохозяйственной техники. Машины почвообрабатывающие. Показатели назначения. Общие требования. - Режим доступа: mcx.ru>documents/file document/v7 show/.

2. Стариев С.В., А.С. Стариеев, Горбань Д.Г. Альбомсправочник по производственной эксплуатации машиннотракторного парка. - Саратов, 2011. - 322 с.

3. Грибановский А.П., Бидлингмайер Р.В. Комплекс противоэрозионных машин (теория, проектирование). - АлмаАта: Кайнар, 1990. - 256 с.
4. Механизация защиты почв от водной эрозии в Нечерноземной полосе / под ред. А.Т. Вагина. - Л.: Колос (Ленингр. отделение), 1977. - 272 с.

5. Зеленин А.Н. Основы разрушения грунтов механическими способами. - М.: Машиностроение, 1968. - 376 с.

Бойков Василий Михайлович, $\partial-p$ техн. наук, проф. кафедры «Процессы и сельскохозяйственные машины в АПК», Саратовский государственный аграрный университет имени Н.И. Вавилова. Россия.

Старцев Сергей Викторович, $\partial-p$ техн. наук, проф. кафедры «Процессы и сельскохозяйственные машины в АПК», Саратовский государственный аграрный университет имени Н.И. Вавилова. Россия.

Павлов Андрей Владимирович, канд. техн. наук, доиент кафедры «Технический сервис и технология конструкиионных материалов», Саратовский государственный аграрный университет имени Н.И. Вавилова. Россия.

Нестеров Евгений Сергеевич, канд. техн. наук, доиент кафедры «Процессы и сельскохозяйственные машины в АПК», Саратовский государственный аграрный университет имени Н.И. Вавилова. Россия.

Башмаков Игорь Андреевич, аспирант кафедры «Проиессы и сельскохозяйственные машины в АПК», Саратовский государственный аграрный университет имени Н.И. Вавилова. Россия.

410056, г. Саратов, ул. Советская, 60.

Тел.: (8452) 73-64-12.

Ключевые слова: почвообрабатывающее орудие; чизельный рабочий орган; тяговое сопротивление.

\title{
DEVELOPMENT OF THE SCHEME OF SOIL TREATMENT TOOLS WITH RATIONAL ARRAY OF CHISEL WORKING BODY
}

Boykov Vasiliy Mihaylovich, Doctor of Technical Sciences, Professor of the chair "Processes and Agricultural Machinery in AIC", Saratov State Agrarian University named after N.I. Vavilov. Russia.

Startsev Sergey Viktorovich, Doctor of Technical Sciences, Professor of the chair "Processes and Agricultural Machinery in APIC", Saratov State Agrarian University named after N.I. Vavilov. Russia.

Pavlov Andrey Vladimirovich, Candidate of Technical Sciences, Associate Professor of the chair "Technical Service and Technology of Structural Materials", Saratov State Agrarian University named after N.I. Vavilov. Russia.

Nesterov Evgeniy Sergeevich, Candidate of Technical Sciences, Associate Professor of the chair "Processes and Agricultural Machinery in AIC", Saratov State Agrarian University named after N.I. Vavilov. Russia.
Bashmakov Igor Andreevich, Post-graduate Student of the chair "Processes and Agricultural Machinery in AIC", Saratov State Agrarian University named after N.I. Vavilov. Russia.

Keywords: tillage tool; chisel working body; traction resistance.

On the basis of the analysis of the known tillage tools various schemes of arrangement on them of working bodies of chisel type are considered. Using the basic provisions of agricultural mechanics and mechanics of soil destruction, the calculations of traction resistance of chisel working bodies interacting with the treated arable layer in conditions of blocked, semi-blocked and free cutting are performed. The scheme of the soil-cultivating tool with rational arrangement of chisel working bodies is developed.

\section{ЭКСПЛУАТАЦИОННЫЕ ОСОБЕННОСТИ КОНСТРУКЦИЙ КОМПОЗИТНЫХ БАЛЛОНОВ С ПОЛИМЕРНЫМ ЛЕЙНЕРОМ}

\author{
КАЛИННИкОВ Александр Николаевич, Межотраслевой инжиниринговый центр «Композиты России» \\ МГТУ им. Н.Э. Баумана, ФГАОУ ВО «Московский государственный технический университет \\ имени Н.Э. Баумана (национальный исследовательский университет)»
}

ЛЕБЕДЕВ Игорь Константинович, ООО «Системы армированных фильтров и трубопроводов» МОРОЗ Николай Григорьевич, ООО «Системы армированных фильтров и трубопроводов»

Проведен анализ возможнъх причин повреждения (трещинообразования) полимерных материалов, используемых для изготовления лейнеров композитных баллонов, оценивается надежность баллонов для хранения LPG данной конструкиии из полиэтилентерфталата. Принципиальное отличие существующих конструкций баллонов LPG различных производителей заключается в конструктивном исполнении внешнего защитного кожуха и внутренней герметизирующей оболочки - лейнера для композитной (стеклопластиковой) оболочки. Показано, что основными причинами трещинообразования в полиэтилентерефталате как силовой оболочки являются технологические и эксплуптационные факторы.

Введение. Существующие в настоящее время баллоны из композиционных материалов, используемые в бытовых целях для хранения LPG, имеют конструктивную схему, в которой лейнер может быть выполнен из полиэтилена (ПЕ) или полиэтилентерефталата (ПЭТ).
Материал силовой оболочки, как правило, стеклопластик на основе эпоксидного или полиэфирного связующего.

Принципиальное отличие существующих конструкций баллонов LPG различных производителей заключается в конструктивном исполнении внешнего 


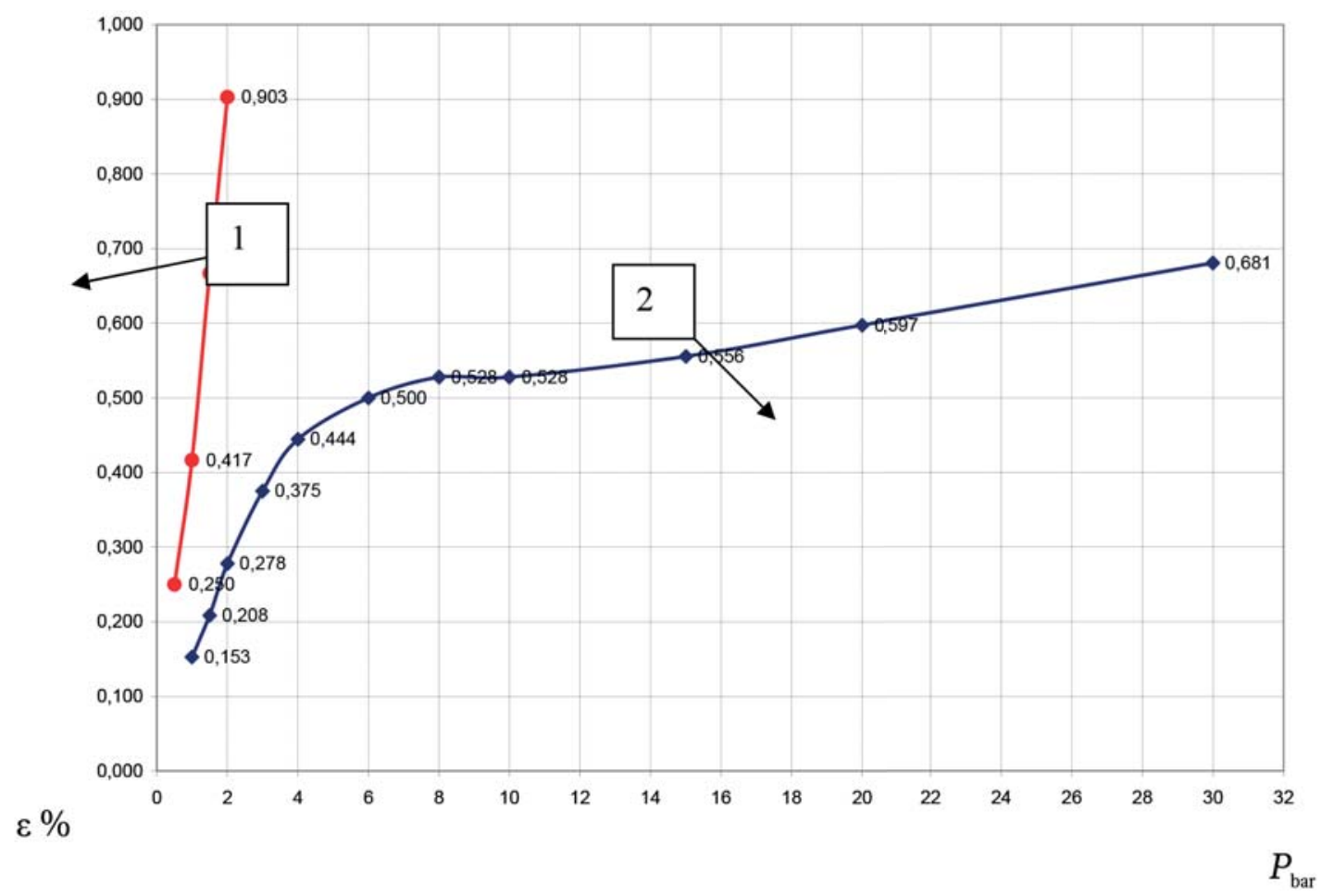

Рис. 1. Деформации ПЕТ лейнера: 1 - в отдельном исполнении; 2 - в составе оболочки

защитного кожуха и внутренней герметизирующей оболочки - лейнера.

Однако использование полимеров типа ПЕ или ПЭТ приводит к частому их разрушению в виде образования локальных трещин в материале лейнера и проявлению течи баллона.

Методика исследований. В работе проводится анализ возможных причин повреждения (трещинообразования) полимерных материалов, используемых для изготовления лейнеров композитных баллонов.

Наиболее предполагаемой версией разрушения ПЭТ лейнера, очевидной для любого наблюдателя, является предположение, что причиной возникновения трещины в ПЭТ материале является недостаточная прочность материала, находящегося под нагрузкой при действии внутреннего давления в баллоне.

Для ответа на поставленный вопрос было проведено исследование прочности лейнера баллона как в отдельном исполнении, так и в составе композитной оболочки.

Такое разделение вызвано тем, что со временем в материале лейнера баллона могут происходить усадки, и между композитной оболочкой и лейнером может образоваться зазор, в результате чего некоторая часть нагрузки от действия внутреннего давления воспринимается материалом лейнера. В связи с этим был поставлен вопрос об определении уровня максимальных деформаций, возникающих в результате такой возможной картины изменения конструкции.

Для ответа на поставленное предположение были проведены испытания на нескольких баллонах обьемом 24 л диаметром 300 мм, где в качестве основных измерений фиксировали избыток рабочей жидкости $\Delta V$, мм $^{3}$, создающей давление в баллоне. На рис. 1 представлена обработанная диаграмма изменения обьема $\left(\varepsilon=\Delta V / V_{0}\right)$ от создаваемого ей давления $P$.

Результаты исследований. Анализ данной диаграммы показывает, что максимально возможный уровень деформации в материале лейнера, находящегося в составе композитной оболочки (2), в интервале рабочего давления достигает уровня 0,7 \%, что значительно выше уровня допустимых для ПЭТ деформаций, устанавливаемого с позиций коррозионного растрескивания.

Элементный анализ прочности лейнера, находящегося в составе композитной оболочки, показывает, что уровень деформаций в зоне горловины баллона достигает $2,0-2,5 \%$. что также значительно превышает уровень деформаций, допустимых для ПЭТ, устанавливаемых с позиций коррозионного растрескивания ПЭТ (см. например ISO 13760).

В качестве второго предположения о возможной причине возникновения трещины в материале лейнера рассматривали вопрос о влиянии ползучести и усадки материала в зоне уплотнения в горловине баллона.

Данные эффекты хорошо подтверждаются при рассмотрении фрагментов готового баллона, прошедшего термообработку при температуре до $95{ }^{\circ} \mathrm{C}$ с внутренним пневматическим давлением до 16 бар, и приводят к возможности образования трещин в материале лейнера (рис. 2). Для материала лейнера, находящегося в кристаллическом состоянии, данный эффект незначительно уменьшается.

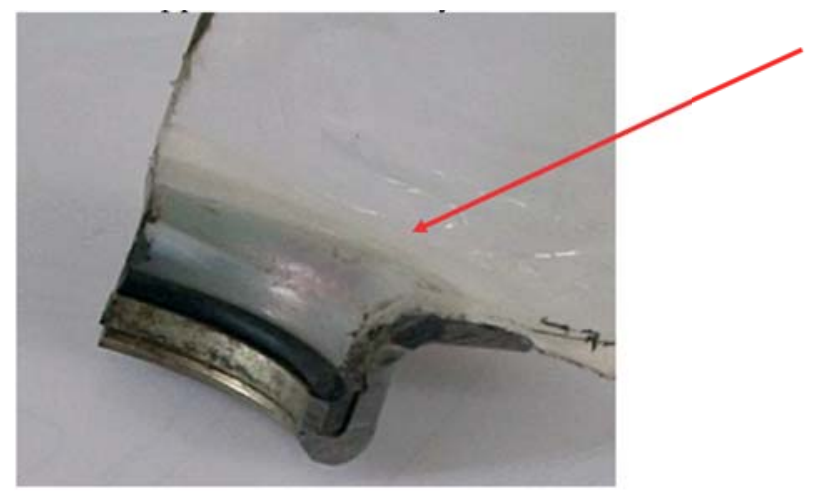

Рис. 2. Ползучесть и усадка материала в зоне уплотнения

Однако при визуальном осмотре внутренней части лейнера в зоне горловины отмечается наличие множества продольных лучей в виде несквозных трещин (рис. 3), образовавшихся при нагружении баллона.

Для проверки влияния данных концентраторов напряжений были из лейнера в данной зоне приготовлены 
образцы материала, которые подвергались механическому растяжению с временной выдержкой (рис. 4).

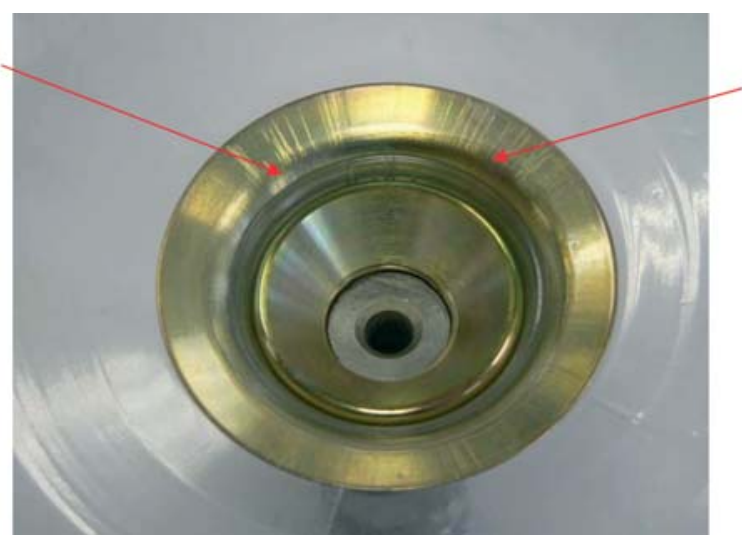

Рис. 3. Несквозные дефекты в ПЭт материале

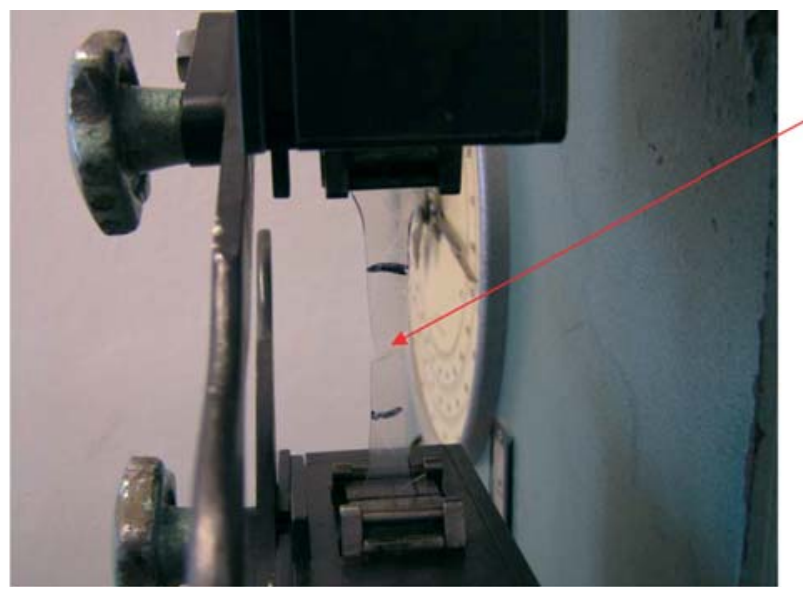

Рис. 4. Образование шейки и разрушение ПЭТ при растяжении

Анализ данных испытаний показал катастрофическое разрушение образцов в данной зоне. Кроме того, следует отметить, что при низких уровнях деформаций в данных лучах материала происходит образование деформационных шеек (см. рис. 4), которые со временем приводят к его разрушению. Наличие таких лучей в материале лейнера является одной из причин, провоцирующих образование трещин в лейнере. Особенно данные эффекты проявляются для материала, находящегося в аморфной фазе.

Химическая стойкость материала лейнера к различного рода средам.

Одной из наиболее вероятных причин проявления трещин является стойкость используемого материала лейнера к различного рода средам, которые контактируют с данным материалом в процессе изготовления баллона или в процессе его эксплуатации.

Для этих целей был проведен ряд экспериментальных испытаний лейнера к воздействию различного рода химических сред.

Испытания проводили в двух условиях: лейнер со средой без пневматического давления внутри и лейнер со средой под давлением. Давление в лейнере создавалось нагнетанием воздуха до давления 1,2 бар и выбрано из условия, что при таком давлении в лейнере, находящемся в свободном состоянии реализуются, деформации материала до уровня 0,6 \%.

В качестве химических сред использовали эпоксидные композиции; 10\%-й раствор $\mathrm{HCl} ; 10 \%$-й раствор $\mathrm{H}_{2} \mathrm{SO}_{4}$; растворители (ацетон, толуол); щелочь $\mathrm{NaOH}$; глицерин; смеси указанных выше эпоксидных композиций с растворителями, а также смеси пропана-бутана.
Указанные смеси заливали в лейнер таким образом, чтобы была перекрыта вся зона, где отмечали проявление трещин. При проведении испытаний оценивали воздействие смесей на горловинную часть лейнера, донную часть лейнера и боковую часть лейнера. Оценку влияния смеси проводили по времени выдержки в контакте со средой. В качестве базового времени принимали время равное 336 ч (две недели выдержки).

Пример наполнения лейнера и преформ для его изготовления некоторыми из рассматриваемых смесей представлен на рис. 5.
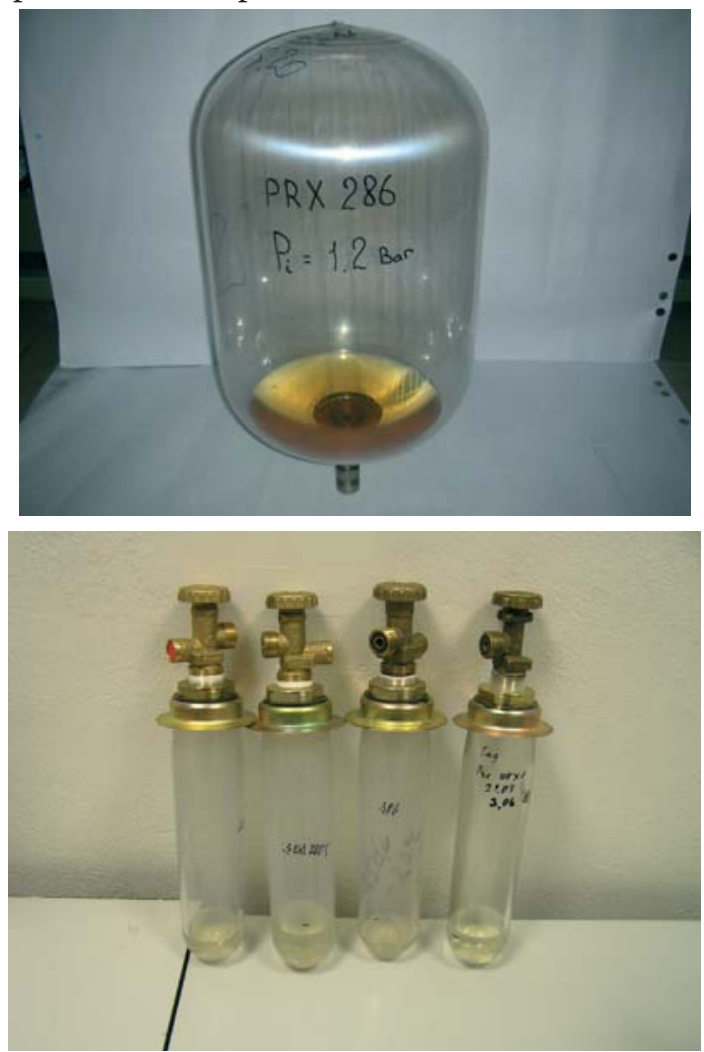

Рис. 5. Наполнение лейнера и преформ смесями газов и жикостей

Смеси пропана - бутана заливали в собранные с вентилем преформы и создавали различные давления путем подогрева преформ.

Следует отметить, что при отсутствии внутреннего давления в лейнере в течение базового периода с материалом лейнера не происходит никаких изменений при прямом контакте с названными средами в любой его зоне.

При наличии пневматического давления в лейнеpe (создании внутренних растягивающих напряжений в материале лейнера) и контакте с отдельными смесями происходит изменение в материале лейнера в виде сквозных и несквозных трещин.

При контакте лейнера с отдельными средами и при наличии в нем внутреннего давления в горловинной части лейнера проявляются трещинообразные дефекты, близкие к найденным в баллонах. К таким смесям относятся: щелочь (5\%-й раствор в воде), ацетон, эпоксидная композиция и ее смесь с ацетоном.

Проявление таких дефектов для разных сред проявляется в разные промежутки времени, от нескольких минут до нескольких часов.

На рис. 6 показан типовой результат воздействия на материал лейнера сред, оказывающих наибольшее влияние на трещинообразование в нем.

Прямой контакт с остальными всеми перечисленными средами не вызывает изменений в материале лейнера. 


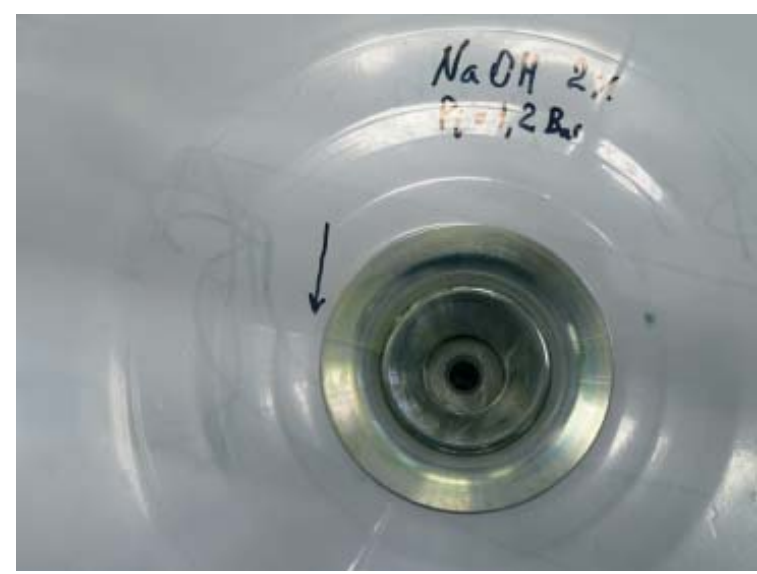

Рис. 6. Прямой контакт со щелочью - проявление трещины в течение 2 мин

Образование несквозных трещин вызвано наличием механических повреждений в преформах и агрессивным воздействием различных сред.

Все отмеченные выше проявляющиеся дефекты в виде сквозных трещин, возникающие при воздействии агрессивных химических сред, происходят только по направлениям данных несквозных трещин. Процесс явно нестабилен и имеет короткий промежуток времени. Данные выводы указывают на то, что одной из основных причиной развития дефектов в виде сквозных трещин является воздействие агрессивной среды на материал, находящийся в высокодеформированном состоянии в локализованных зонах.

Следует также отметить, что образовавшиеся несквозные трещины развиваются при длительном нагружении материала лейнера. Это указывает на то, что трещина может возникнуть как при первом нагружении баллона, так и при любом последующем. В отдельных случаях лейнер с имеющимися несквозными трещинами может быть герметичен длительное время, соизмеримое со временем жизни баллона.

Испытания качества изготовленных преформ проводили методом воздействия водного раствора $\mathrm{NaOH}$ или ацетона на напряженный материал преформы. Напряжения создавали путем натяга преформы на металлическую втулку. Деформация материала преформы в таком состоянии составляла 4 \%. Качество изготовления преформ оценивали по времени проявления трещин при одновременном воздействии химически активной среды и силового поля.

Трещины возникают в химически необработанной преформе, содержащей локальные дефекты в виде продольных линий или царапин. Время развития таких трещин в ПЭТ материале с внутренней вязкостью 0,76 составляет не более 1 мин. Локализация и развитие трещин в данном случае всегда находится в переходной зоне префомы. Время проявления трещин в преформах, изготовленных из ПЭТ-гранулята с более высокой внутренней вязкостью значительно увеличивается. Так, для гранулята с внутренней вязкостью 0,80 время развития таких трещин в данном материале составляет более 1 ч.

Аналогичная картина поведения материала возникает и в химически необработанной преформе, но имеющей кристаллизованную зону.

Анализ проведенных наблюдений показывает, что в зоне горловины преформы имеется неравномерное поле внутренних напряжений, возникающих при переработке материала в преформу.

Кроме того, в процессе переработки полимера в преформы возможна деградация полимера (разрыв длинных молекул на более короткие) или использование смеси первичного и вторичного полимера, что в конечном итоге увеличивает вероятность образования крейзов при одновременном воздействии растягивающих напряжений и адгезивно активной среды.

Физика образования трещин в материале ПЭТ лейнера.

Как следует из вышесказанного, несмотря на достаточно хорошие интегральные механические свойства и характеристики, общим недостатком ПЭТ является его деструкция в контакте с газами и жидкостями, связанная с явлением диффузии среды в полимер.

Известно, что аморфные полимеры являются структурно неоднородными телами с размерами неоднородностей порядка десятков ангстрем. Неоднородность структуры аморфных полимеров носит не фазовый, а флуктуационный неравновесный характер. Кроме того, в области предела текучести деформация полимера существенно неоднородна по объему.

Наряду с полосами сдвига в полимере возникают видимые и другие зоны пластической деформации, которые называют крейзами.

Наличие поверхностно активной среды (например, воды, воздуха и др.) в контакте с полимером существенно усугубляет отмеченные выше явления деформирования ПЭТ и приводит к его деструкции.

Суть явления состоит в том, что среда, проникая в материал за счет диффузии и молярного переноса по дефектам структуры полимера, способствует повышению подвижности структурных элементов, играя роль смазки, что способствует разрыву связей в макромолекулах полимера, разрыхлению его структуры, его охрупчиванию и появлению локальных трещин.

Проявление таких дефектов - временной процесс, и для разных сред проявляется в промежутки времени от нескольких часов до нескольких дней.

Описанный процесс обычно называют коррозионным растрескиванием полимеров, и он является одним из самих распространенных типов разрушения полимеров, определяющий области их использования.

В многочисленных исследованиях полимеров показано, что если уровень внутренних напряжений в полимере составляет порядка 0,2-0,35 от предела его текучести, то диффузионные характеристики в полимере практически не изменяются. С повышением уровня внутренних напряжений процесс переноса среды в материал резко ускоряется, что связано с началом образования при этих напряжениях микроразрывов в полимере.

Таким образом, практически основной характеристикой полимеров в конструкциях, работающих под нагрузкой, является максимальное допустимое значение усилий или деформаций растяжения в полимере, которые способен выдерживать полимер в течение заданного срока службы, или стойкость к медленному распространению трещин при заданных температурах и заданном начальном напряжении в материале, выражаемая в часах.

Очевидно, что различного рода среды, которые контактируют с полимерным материалом в процессе изготовления лейнера баллона или в процессе эксплуатации баллона, по-разному влияют на процесс трещинообразования полимера, находящегося под нагрузкой. Наиболее чувствительны полимеры к растворителям, щелочам и другим активным средам.

Кроме отмеченного, при циклических нагружениях полимеров происходит их разрушение в силу так называемого «кессонного» эффекта. В данном случае среда при повышенном давлении диффундирует в структуру поли- 
мера, а после снятия нагрузки давление продиффундировавшей во внутрь полимера среды разрывает полимер.

Существенное влияние оказывает и температура, при которой находится полимер при деформировании.

При эксплуатации баллонов с газом при низких температурах (от -4 до $-40{ }^{\circ} \mathrm{C}$ ) в баллоне возможно образование вакуума за счет перехода газа из газообразного состояния в жидкую фазу. В данном случае лейнер теряет устойчивость и начинает сжиматься в виде произвольной формы с образование складок. При таком сжатии лейнер за счет трения образовавшихся складок и ребер о стенки композитной оболочки получает механические повреждения в виде сквозных рваных отверстий, что приводит к катастрофической потере герметичности баллона.

Заключение. На основании вышеизложенного можно сделать следующие выводы.

Полиэтилентерефталат явяется очень нестабильным материалом с позиций коррозионного растрескивания под нагрузкой.

Основной причиной трещинообразования в полиэтилентерефталате являются технологические и эксплуптационные факторы.

Использование таких материалов для высоконагруженных конструкций крайне нежелательно.

В силу отмеченных явлений, происходящих с полиэтилентерефталатом, который используется в качестве базового материала для лейнера в конструкциях баллонов LPG надежность баллонов такой конструкции крайне низкая.

Практически аналогичные эффекты находят место и при использовании в качестве материала лейнера полиэтилена. В данном случаен проявляются еще дополнительные эффекты, связанные с структурой ПЕ.
Использование материалов типа ПЕ или ПЭТ в качестве основных для изготовления лейнеров баллонов давления является крайне нежелательным, особенно для баллонов высокого давления (рабочее давление более 20 бар).

Настоящая статья выполнена в рамках договора № 02.G25.31.0175 «Разработка новых импортозамещающих технологий производства металлокомпозитных емкостей и баллонов высокого давления с применением высокоточного позиционирования заготовок, микроплазменной сварки и программно-аппаратной интеграции и оптимизации параметров технологчческого процесса изготовления и испытаний», финансируемого Министерством образования и науки Российской Федерации.

Калинников Александр Николаевич, зав. лабораторией, Межотраслевой инжиниринговый иентр «Композиты России» МГТУ Им. Н.Э. Баумана, ФГАОУ ВО «Московский государственный технический университет имени Н.Э. Баумана (национальный исследовательский университет)». Россия.

105005, г. Москва, ул. 2-я Бауманская, 5.

Тел.: (499) 263-63-91.

Лебедев Игорь Константинович, канд. техн. наук, ООО «Системы армированных фильтров и трубопроводов» («САФИТ»). Россия.

Мороз Николай Григорьевич, канд. техн. наук, ООО «Системы армированных фильтров и трубопроводов» («САФИТ»). Россия.

141351, Московская область, Сергиево-Посадский $p$-н, д. Жучки, $2 \partial$.

Тел.: (495) 989-48-42.

Ключевые слова: баллоны высокого давления; полиэтилентерефталат; лейнер; композит; дефект.

\title{
OPERATIONAL FEATURES OF DESIGNS OF COMPOSITE CYLINDERS WITH A POLYMER LINER
}

Kalinnikov Alexander Nikolayevich, Head of laboratory, Intersectoral Engineering Center "Composites of Russia”, Bauman Moscow State Technical University. Russia.

Lebedev Igor Konstantinovich, Candidate of Technical Sciences, JSC "Reinforced Filters and Pipelines Systems" (SAFIT). Russia.

Moroz Nikolai Grygoryevich, Candidate of Technical Sciences, JSC "Reinforced Filters and Pipelines Systems" (SAFIT). Russia.

Keywords: high pressure cylinders; polyethylene terephthalate; linear; composite; defect.

This article analyzes the possible causes of damage (cracking) of polymer materials used for the manufacture of composite cylinder liners and assesses the reliability of LPG storage cylinders of this design of polyethylene terphthalate. The principal difference between the existing LPG cylinder designs of different manufacturers is the design of the outer protective casing and the inner sealing liner for the composite (fiberglass) shell. It is shown that main causes of cracking in polyethylene terephthalate are technological and operational factors.

DOI

удК 658.265

\section{ОБОБЩЕННЫЕ ПРЕДЛОЖЕНИЯ ПО РЕКОНСТРУКЦИИ ВОДОПОДГОТОВИТЕЛЬНЫХ УСТАНОВОК ДЛЯ ПРОИЗВОДСТВЕННЫХ КОТЕЛЬНЫХ}

\author{
КАТКОВ Данила Сергеевич, Саратовский государственный аграрный университет имени Н.И. Вавилова \\ ЖУкОВ Александр Викторович, Саратовский государственный аграрный университет \\ имени Н.И. Вавилова
}

В статье изложен опыт внедрения энергосберегающих технологий и систем автоматизации работы котельной, даны научно обоснованные рекомендации в области технико-экономического обоснования и реконструкции котельных, модернизации производственных котельных, обеспечениz безопасности и экологичности работы производственной котельной и ее соответствия требованиям надзорных органов.

Введение. Проблема эффективного отопления производственного предприятия с одновременным экономичным теплообеспечением различных тех- нологических процессов в настоящее время крайне актуальна [9]. Теплоснабжение промышленных предприятий - обеспечение теплом по месту его потреб- 